\title{
Response of the Middle Atmosphere to Solar Variability - Model Simulations
}

\author{
By THERESA Y. W. HUANG AND GUY P. BRASSEUR
}

National Center for Atmospheric Research, Boulder, CO 80307, USA

Solar flux variations could affect the middle atmosphere through modulating the photolysis of chemical series and solar heating rates. Indirect feedback effects from chemical, radiative, and dynamical interactions could provide additional sources for perturbations in the middle atmosphere. In this paper, recent developments in modeling the effect of solar variability on the middle atmosphere is described. For the 27-day solar rotational cycle, the temperature and ozone response in the stratosphere predicted by one- and two-dimensional models compares well with data analyses. For the 11-year solar cycle, model simulations suggest a non-negligible ozone/temperature response compared to changes produced by anthropogenic perturbations in the stratosphere. There is no sufficient long-term atmospheric dataset to establish a statistically significant correlation with the 11-year solar cycle. But in general, agreement between the observational analysis (for periods of one to two solar cycles) and model simulations of the long-term solar variability effect is unsatisfactory.

\section{Introduction}

Understanding how solar flux variations affect our atmosphere provides a way to learn about the interactive processes among the photochemistry, dynamics and radiation in the middle atmosphere. The long-term trends of temperature and ozone associated with anthropogenic perturbations can be more accurately estimated if the long-term changes caused by solar variability are well understood. Until recently, modeling the response of the middle atmosphere to solar variability had been impeded by the absence of reliable solar flux measurements, and by the lack of observational data required for meaningful model verification. With satellite measurements made during the past decade, more information is available regarding the cyclic variation of solar irradiance and relevant atmospheric data. This warrants a look into the effect of solar flux variation on the middle atmosphere from a model simulation perspective.

The electromagnetic flux emitted by the Sun varies with time predominantly in the 27day and 11-year time period. Changes in solar irradiance on the 27-day solar rotational time scale arise from the uneven distribution of the active regions on the Sun. The longterm irradiance changes related to the 11-year solar cycle are caused by the changing emission of bright magnetic features, such as faculae and the magnetic network. Shown in Figure 1 is the time evolution of solar flux from observations by the Solar Mesosphere Explorer (SME), between the period 1982 - 1988 for the Lyman- $\alpha$ line $(121.6 \mathrm{~nm})$, $\mathrm{O}_{2}$ Schumann-Runge bands (180-200 nm), and the $\mathrm{O}_{2}$ Herzberg continuum (205 nm) (extracted from Brasseur 1993). Enveloped within the long-term variation of the solar flux are the short-term oscillations corresponding to the Sun's rotational period. The variability of the solar irradiance as a function of wavelength, as estimated by Rottman (1988), is shown in Figure 2a for the 11-year solar cycle and in Figure 2b for the 27-day solar variability. The largest change seen in the solar flux is in the Lyman- $\alpha$ line; the variability decreases substantially with increasing wavelength, with negligible variations beyond $300 \mathrm{~nm}$. A large uncertainty in the solar flux variation shown in Figure 2a arises from the fact that SME data cover less than one solar cycle period. The long-term drift that may occur in solar detectors is also a cause of concern. In fact, for the $200-210 \mathrm{~nm}$ 
SME SOLAR FLUX

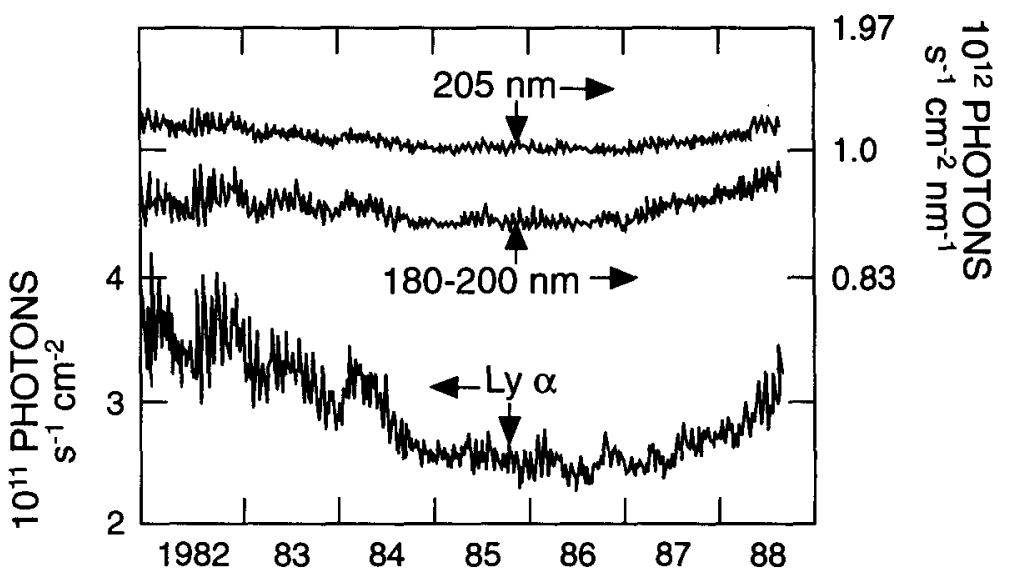

FIGURE 1. Solar actinic flux measure by the Solar Mesosphere Explorer at different wavelengths (121.6 nm, 180-200 nm, $205 \mathrm{~nm}$ ) between 1982 and 1988, from Brasseur (1993).

region that is important to the photochemistry of the stratosphere, major uncertainties exist regarding the magnitude of the 11-year solar flux variability from a low $5 \%$ reported by Rottman (1988) to a high $10 \%$ described by Deland \& Cebula (1993).

Observational studies that correlate the ozone/temperature temporal variability with variations in the solar irradiance suggest a connection between the solar cycle and the thermal and chemical structure of the middle atmosphere. This is especially true for the short-term variation, as revealed by analyses based on satellite observations in the 1980's (Gille et al. 1984; Hood 1986; Keating et al. 1987; Hood et al. 1991; and Hood \& Jirikowic 1991). Convincing statistics are more difficult to obtain for the 11-year solar cycle response since reliable measurement records for the middle atmosphere span only slightly more than one solar cycle. Recent satellite data analyses of ozone, however, suggest a likely correlation with the long-term solar cycle (Chandra 1991; Stolarski et al. 1991; Hood \& McCormack 1992; Hood et al. 1993), as do observations of stratospheric temperature measured by radiosondes (Labitzke et al. 1986; Angell 1988, 1991), rocketsondes (Angell 1991) and lidar (Hauchercorne \& Chanin 1980; Chanin et al. 1987).

The effects of solar variability on the dynamics of the middle atmosphere still remain a matter of discussion. Labitzke \& van Loon (1988) suggest an association between the 11-year solar cycle and the stratosphere, based on the analysis of more than three solar cycles of temperature and geopotential height data. Their correlation appears to be affected by the phase of the quasi-biennial oscillation (QBO). This study was followed by a series of statistical analyses on tropospheric temperature and pressure fields (van Loon \& Labitzke 1988; Labitzke \& van Loon 1989), in which relationships with solar activity were also found. Later studies such as those of Baldwin \& Dunkerton (1989), and Salby \& Shea (1991) argue against a physical explanation underlying these statistical correlations. Kodera (1993), however, calculated the correlation of the relationship between temperature and zonal wind and showed that a quasi-decadal variation can be seen without decreasing the sampling frequency. This implies that aliasing due to undersampling is not the primary cause of the correlation found by Labitzke \& van Loon (1988). Another development that indicates the importance of dynamical feedback effect is the finding by Kodera \& Yamazaki (1990) of large December zonal wind variations 


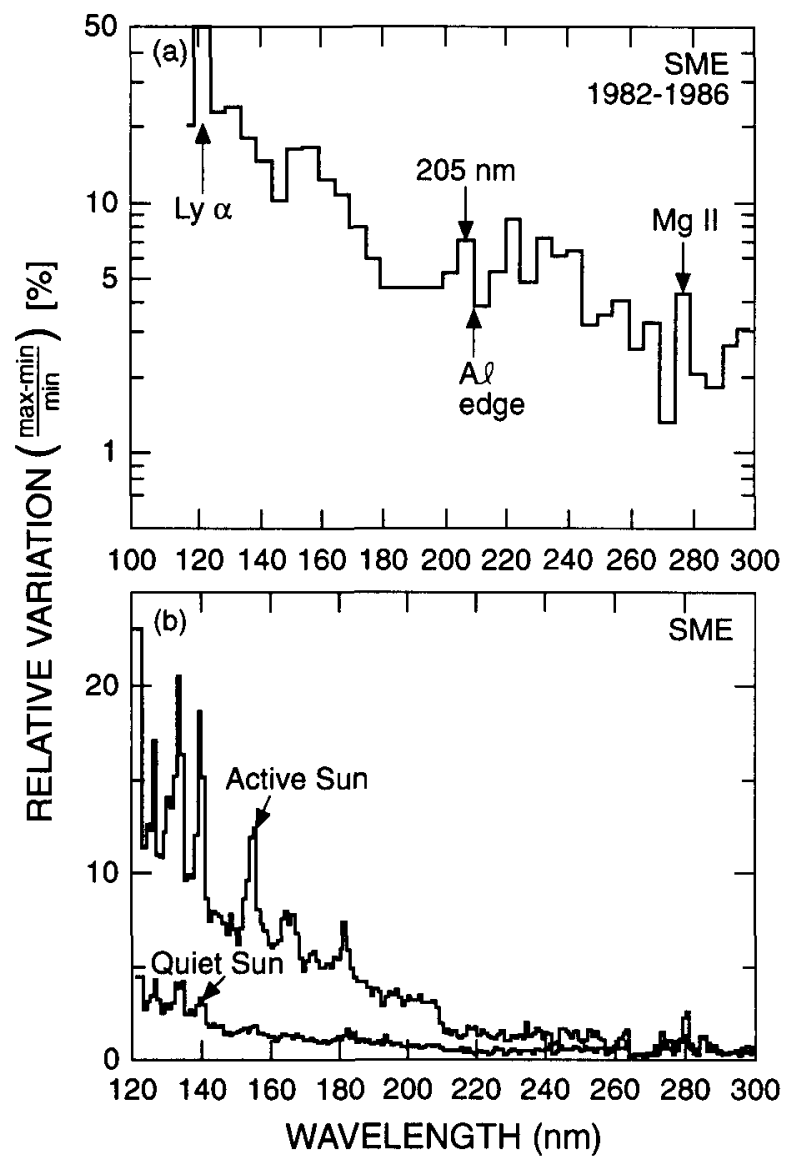

FIGURE 2. Variation (\%) in solar ultraviolet flux as a function of wavelength derived from measurements by the Solar Mesosphere Explorer. (a) Variation between solar maximum and solar minimum conditions (11-year cycle); (b) Variation over a solar rotation period (27-day) for active and quite Sun, respectively, from Brasseur (1993).

tude) with solar activity in the upper stratosphere at $40^{\circ} \mathrm{N}$. Hood et al. (1993) found a similar but somewhat smaller winter solstice zonal wind variation $(14 \mathrm{~m} / \mathrm{s})$ for the Southern Hemisphere.

Theoretically, the modulation of the solar radiation can affect the structure of the atmosphere several different ways. The most direct is through changes in the solar heating rate and the photodissociation frequency of the photochemical species; these effects would be seen mainly in the higher altitude region (the mesosphere and thermosphere) since the larger changes in the solar flux occur at wavelengths shorter than $200 \mathrm{~nm}$. Although these shorter wavelengths are unable to penetrate into the lower stratosphere, the intricate coupling of photochemistry, radiation, and dynamics in the middle atmosphere may make it possible for the solar variability to affect the lower altitudes of the middle atmosphere through some feedback mechanisms. For example, changes in solar irradiance in the Schumann-Runge bands and Herzberg continuum can affect the photodissociation of molecular oxygen in the mesosphere and stratosphere, which in turn influence ozone abundance. A change in the ozone concentration would affect both the long-wave and short-wave radiative heating which force changes in the temperature, and therefore could affect the meridional circulation and wave activity. The radiative/dynamical changes 
could then potentially feedback on the ozone balance to modulate the ozone response to the solar variability. Another factor that would allow a response to occur in a region of the atmosphere where the direct impact of solar variability is small is the transport of long lived trace gases from their source regions to other areas. One such example is provided by the odd nitrogen compounds, which are produced through ionic processes in the thermosphere (highly dependent on solar activity) and are transported down to the stratosphere in the polar night. This might directly contribute to the destruction of ozone in the middle to upper stratospheric region when sunlight is present. Another candidate for a feedback process is provided by the effect of wave-mean flow interactions. Zonal wind changes caused by solar variability may trigger changes in the pattern of wave propagation and the magnitude of wave forcing, which could affect the thermal structure of the atmosphere and the zonal wind.

With all the direct solar variability and potential feedback mechanisms operating in the atmosphere, a model simulation is valuable since it enables us to unambiguously test out the connections between solar variability and the atmospheric response within a chosen physical and chemical framework. Through the construction of a model with various degrees of complication, and with the increasing availability of data for comparison, we should be able to identify the major mechanisms that produce the atmospheric response to solar variability. Although it is too early to draw final conclusions about the solar-atmospheric relationship, considerable progress has been made towards our understanding of how solar variability may affect the middle atmosphere. A review will be presented here with the emphasis on model development.

\section{Short-term solar variability}

With the availability of satellite measurements in the last decade, a statistically significant relationship between 27-day variations in the solar flux and atmospheric quantities, such as ozone concentration and temperature, has been established. A simulation of the response of the atmosphere to the 27-day solar cycle is a good starting point for understanding the fundamental processes underlying the solar-atmospheric relationship.

Early modeling efforts have mainly been focused on using one-dimensional photochemical models to interpret the satellite data analyses (Eckman 1986; Brasseur et al. 1987; Summers et al. 1990). From a simplified, linearized continuity equation of ozone perturbation without considering temperature feedback, it can be shown that the ozone response is proportional to the $\mathrm{O}_{2}$ photodissociation frequency (Hood 1986; Brasseur et al. 1987). The sensitivity of ozone and temperature relative to the solar flux change at $205 \mathrm{~nm}$ is therefore a good indicator of the stratospheric response to solar variability. The temperature and ozone response predicted by these one-dimensional models are in reasonable agreement with observational data for the stratosphere. For example, Figure 3 shows the temperature and ozone response and their phase lags relative to the $205 \mathrm{~nm}$ percentage change of solar irradiance calculated from the model of Brasseur et al. (1987) and compared with observations estimated by Hood (1986) and Keating et al. (1987). At $1 \mathrm{mb}$, the model predicts a $0.05 \%$ change of temperature relative to a $1 \%$ change in $205 \mathrm{~nm}$ flux, consistent with Hood's (1986) data analysis $(0.05$ to $0.07 \%)$. The calculated temperature phase lag (Figure $3 \mathrm{~b}$ ), however, is approximately a factor of 2 smaller than the values derived from observations. In an earlier work, Hood (1986), based on a simple analytic model, also showed a factor of 2 discrepancy between the predicted and observed phase lags. He concluded that the discrepancy is due to the neglect of dynamical coupling. The inability of the photochemical-radiative model to properly simulate the temperature phase lag explains why the ozone sensitivity and phase lag (shown in 

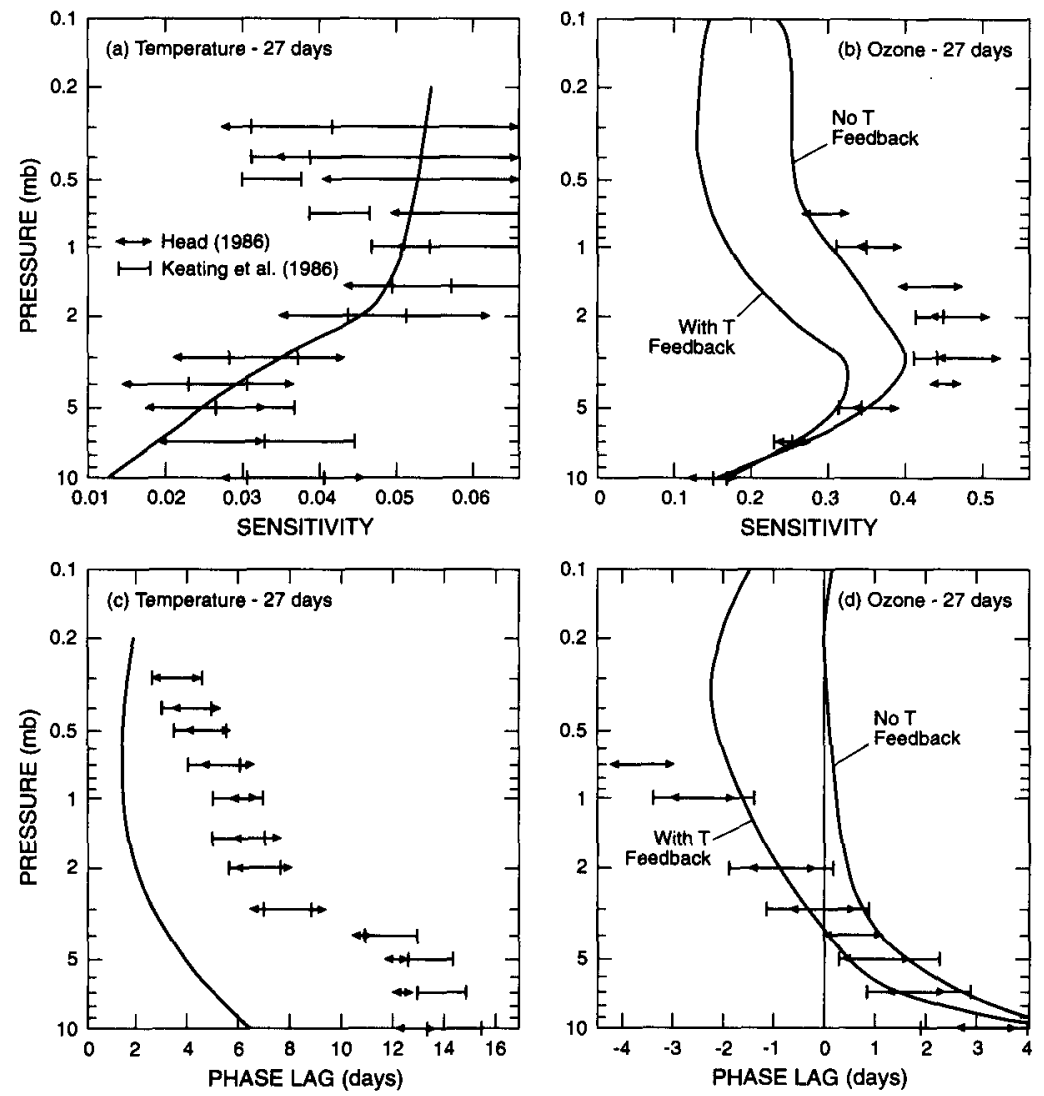

Figure 3. a. Amplitude of temperature variation (expressed in percent of the background temperature) calculated in response to a variation in the solar irradiance of $1 \%$ at $205 \mathrm{~nm}$, with a period of 27 -day. b. Same as a., except for ozone variation. c. Same as a., except for temperature phase lag (expressed in days) d. Same as a, except for ozone phase lag (expressed in days), from Brasseur et al. (1987).

Figure $3 \mathrm{~b}$ and $3 \mathrm{c}$ ) cannot be more accurately modeled. Nevertheless, the calculations illustrate the effect of temperature feedback on the ozone phase lag. Observations show a negative phase lag (e.g. ozone peak ahead of the solar flux peak) above the level of $3 \mathrm{mb}(\sim 40 \mathrm{~km})$, and the model is able to simulate this behavior only when the temperature feedback effect is included. This is because the negative phase lag is mainly a result of the inverse temperature dependence of ozone due to HOx chemistry in the upper stratosphere.

In the mesosphere the ozone response to solar variability is primarily forced by the photolysis of water vapor at Lyman- $\alpha(121.6 \mathrm{~nm})$, which produces hydroxyl radicals and hydrogen atoms that contribute to the ozone destruction. Summers et al. (1990) used a one-dimensional photochemical-radiative model to investigate the mesospheric response to solar flux variations. A comparison between the calculated ozone response (Figure 4a) with the results of Keating et al. (1987) reveals that the observed ozone response is well reproduced when the vertical eddy mixing coefficient used in the model is a factor of 5 smaller than the observationally inferred values. This suggests either a much smaller water vapor mixing ratio in the mesosphere or a less efficient HOx catalytic removal of 

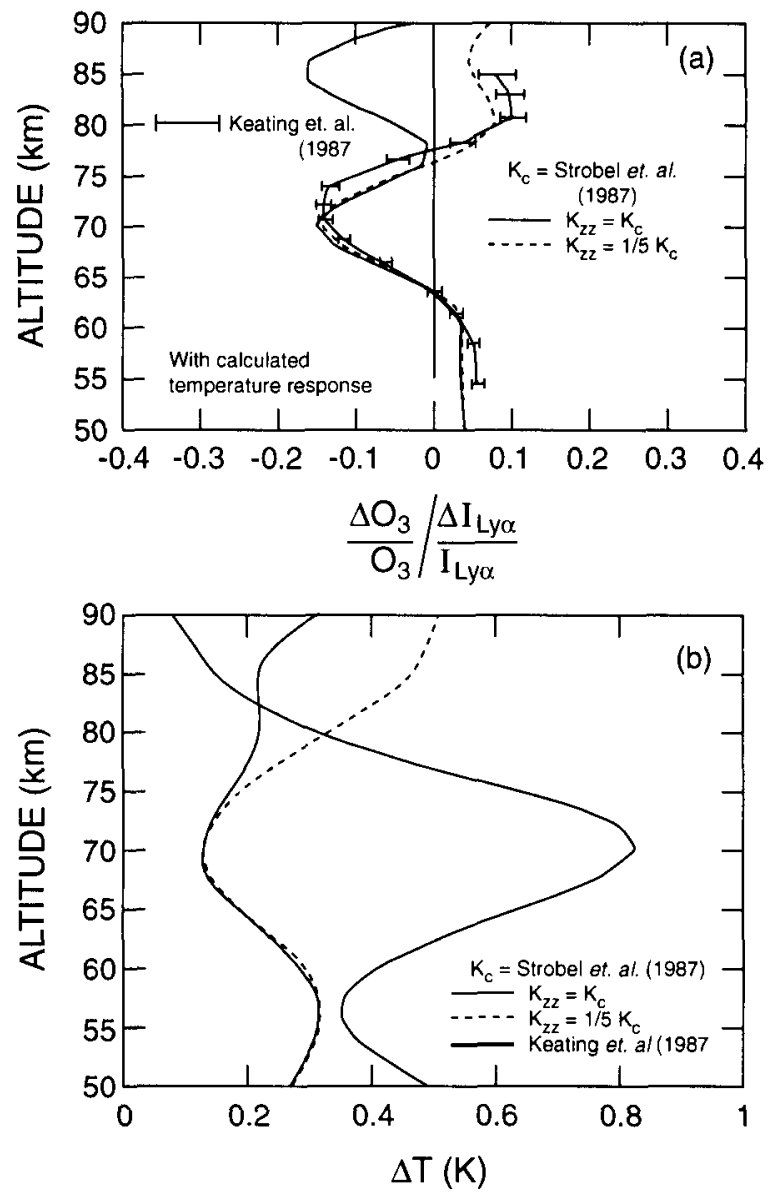

FIgURE 4. a. Ozone response (expressed in percent of background ozone) in response to a variation in the solar irradiance of $1 \%$ at $121.6 \mathrm{~nm}$, for a 27 -day sinusoidal variation of solar UV flux, using the baseline model Kzz profile, and $\mathrm{Kzz}$ decreased by a factor of 5 . b. Temperature response $\left({ }^{\circ} \mathrm{K}\right)$ for corresponding Kzz profiles, from Summers et al. (1990).

ozone than currently accepted. The most significant discrepancy between the models and observations in the mesosphere, however, is the inability of models to produce the positive correlation between temperature and solar activity in the vicinity of $70 \mathrm{~km}$, opposite to that of ozone and solar activity, as seen in Figure 4b (Keating et al. 1987; Hood et al. 1991). Hood et al. (1991) suggested that HOx chemical heating (not included in the model of Summers et al. 1990) could explain this discrepancy, but Huang \& Brasseur (1993) pointed out that the HOx chemical heating is weak near $70 \mathrm{~km}$. Hood et al. (1991) also suggested that dynamical feedback, that is not adequately described in the models, may play a role.

The discrepancies between the one-dimensional model predictions and observations of the solar effects require that more elaborate models be used to establish the mechanisms responsible for the observed atmospheric response to solar variability. A twodimensional model with a formulation of coupled chemical, radiative and dynamical processes could account for potential feedbacks not simulated by simple one-dimensional models. Brasseur (1993) used such a model to investigate the temperature and ozone 


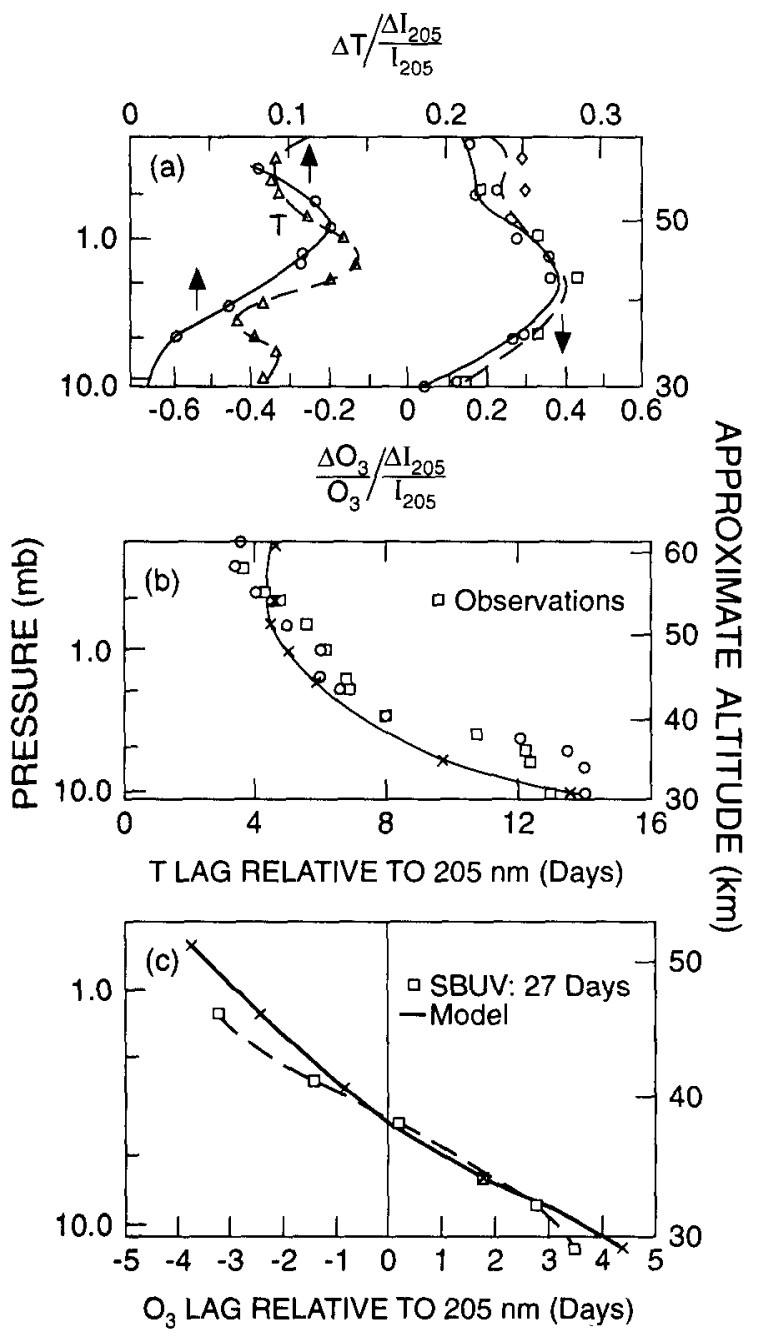

FIGURE 5. a. Ozone and temperature sensitivities relative to a $1 \%$ variation (27-day) in solar flux at $205 \mathrm{~nm}$ (expressed in units of percentage for ozone, and ${ }^{\circ} \mathrm{K}$ for temperature). Calculated values representative of equatorial regions are compared with data analyzed by Keating et al. (1987). b. Calculated time lag (days) of the temperature signal relative to the 27-day solar forcing, compared with observations data (Hood 1986; Keating et al. 1987). c. Calculated time lag (days) of ozone signal relative to the 27-day solar forcing, compared with observational data (SBUV) analyzed by Keating et al. (1987), from Brasseur (1993).

response associated with the solar rotational cycle. Shown in Figure 5a-c are the amplitudes and phases of the ozone and temperature responses in the stratosphere calculated at the equator by Brasseur (1993), compared to an analysis of data averaged over $\pm 20^{\circ}$ latitude (Hood 1986; Keating et al. 1987). The calculated ozone sensitivity is of the order of $0.06 \%$ relative to a $1 \%$ increase in solar irradiance at $205 \mathrm{~nm}$ at $30 \mathrm{~km}, 0.38 \%$ at $40 \mathrm{~km}, 0.25 \%$ at $50 \mathrm{~km}$. The calculated temperature sensitivity is $0.01^{\circ} \mathrm{K}$ per $1 \%$ increase in the $205 \mathrm{~nm}$ solar flux at $30 \mathrm{~km}, 0.06^{\circ} \mathrm{K}$ at $40 \mathrm{~km}$. The overall agreement with the data is good. The phase lags for the temperature and ozone (Figure $5 \mathrm{~b}$ and $5 \mathrm{c}$ ) calculated by the $2-\mathrm{D}$ model are also in much better agreement with observations than those derived by 1-D models (Figure 3). The ozone response in the mesosphere (50 to 80 


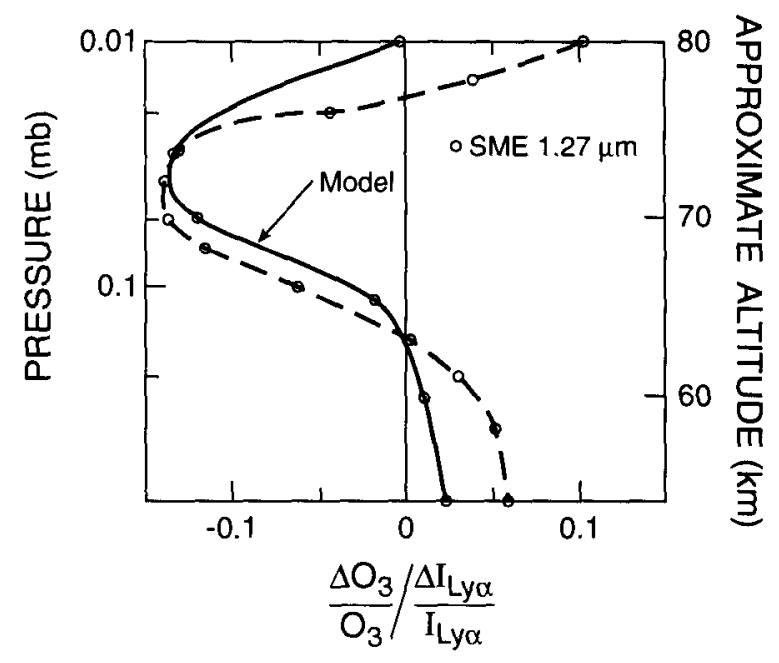

FIGURE 6. Ozone response in the mesosphere relative to a $1 \%$ variation (27-day) solar flux at $121.6 \mathrm{~nm}$ (expressed in percentage). Calculated values compared to the analysis by Keating $e t$ al. (1987), from Brasseur (1993).

$\mathrm{km}$ altitude) is shown in Figure 6. It is expressed relative to the solar flux at Lyman- $\alpha$, since the influence of Lyman- $\alpha$ becomes dominant in this region of the atmosphere. The model and observation compares well for mesospheric ozone. Because the radiative and thermal processes important for the mesosphere are not included in the model used by Brasseur (1993), the response of the temperature in the mesosphere cannot be accurately represented by this model. However, Huang \& Brasseur (1993) used an extended-altitude version of the model, with a more detailed description of the radiative processes of the mesosphere, and derived the steady-state ozone and temperature response to solar flux change. Even with this more detailed formulation, they could not reproduce the opposite response of temperature and ozone observed at $70 \mathrm{~km}$. Although it was a steady-state simulation, it seems unlikely that using a sinusoidal variation of solar flux would alter the overall picture. Assuming that the observed responses in the mesosphere are indeed related to the solar cycle, it appears that either some important dynamical effect has been ignored, or the current understanding of the photochemical or radiative process is flawed and/or incomplete in the mesosphere. It is clear that much more remains to be learned.

\section{Long-term solar variability}

The hypothesis that the 11-year solar cycle modulates the ozone concentration and temperature structure has been discussed for decades, and many theoretical studies have been performed to estimate the effect of long-term solar variability on the middle atmospheric climatology (Callis \& Nealy 1978; Penner \& Chang 1978; Natarajan et al. 1981; Brasseur \& Simon 1981; Garcia et al. 1984; Callis et al. 1985; Wuebbles et al. 1991; Brasseur 1993; Brasseur \& Huang 1993, and references therein). Although the lack of data that covers a sufficiently long period of time precludes an evaluation of the accuracy of the numerical investigations, most models have consistently predicted a small, 


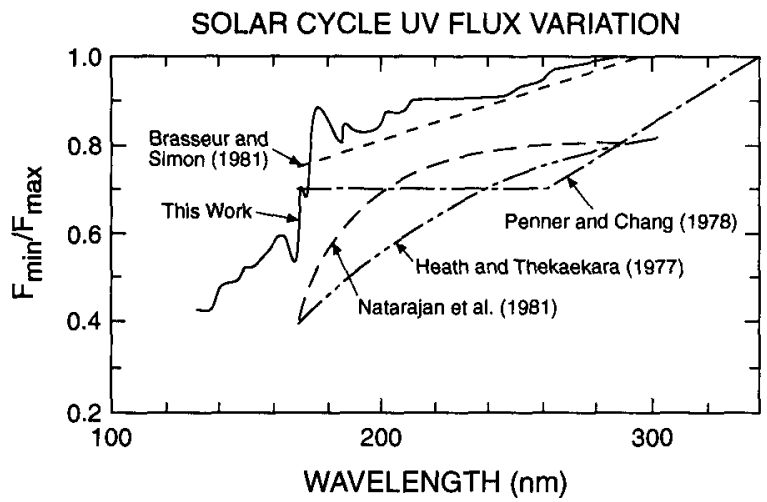

FIGURE 7. Solar flux variation ratio (flux solar minimum/flux solar maximum) adopted in Garcia et al. (1984) and several other studies, from Garcia et al. (1984).

but non-negligible response of the stratosphere to the 11-year solar cycle when currently accepted long-term solar flux variation values are used in the models.

A one-dimensional photochemical-radiative models have been used by Callis \& Nealy (1978), Penner \& Chang (1978), and Natarajan et al. (1981) to simulate the effect of the 11-year solar variability on the chemical and thermal structure of the stratosphere. In the study of Penner \& Chang (1978), the ratio of solar flux between solar minimum and solar maximum at $210 \mathrm{~nm}$ ranges between 0.6 to 0.8 ; a similar value (around 0.7 ) is used in the work of Natarajan et al. (1981). Currently accepted values range from 0.9 to 0.95 . As a consequence of these large changes that were assumed in their models, the change of ozone and temperature from solar minimum and maximum conditions can be quite large. For example, in Penner \& Chang (1978), an ozone change of more than $10 \%$ is predicted at $30 \mathrm{~km}$, and a temperature change of around 2 to $10^{\circ} \mathrm{K}$ is calculated in the stratosphere; a total ozone change of $6.5 \%$ is determined by Natarajan et al. (1981).

Using a photochemical-radiative two-dimensional model with specified dynamical conditions, Brasseur \& Simon (1981) calculated the chemical and thermal response of the stratosphere to solar variation. An updated solar flux variation is used that is considerably larger than the solar minimum and maximum flux ratio assumed by Penner \& Chang (1978) and Natarajan et al. (1981). Brasseur \& Simon (1981) simulated an ozone response that is generally less than $10 \%$, a total ozone variation on the order of $3 \%$, and a temperature response of $2-4^{\circ} \mathrm{K}$ in the stratosphere. Garcia et al. (1984) used a twodimensional model with coupled photochemistry, radiation, and circulation, and showed that the temperature and ozone response in the stratosphere to be even weaker, with a maximum temperature change of less then $2.5^{\circ} \mathrm{K}$, and a maximum ozone change of less than $5 \%$ in the tropical stratosphere. This is partly a result of the even smaller solar UV flux variation used in their work, as evident from Figure 7 (extracted from Garcia et al. 1984). An exception to the weak stratospheric response is seen at the high latitude region in the southern hemisphere during the winter-spring transitional period (see Figure 8), where an ozone reduction of up to $40 \%$ is simulated. This is a direct consequence of the large variation of thermospheric NOx produced by auroral particle precipitation that is included in their model. Large amounts of NOx (during solar maximum condition), that are transported down from the thermosphere during winter, interact photochemically in the stratosphere to give a large ozone reduction after the return of solar insolation. 


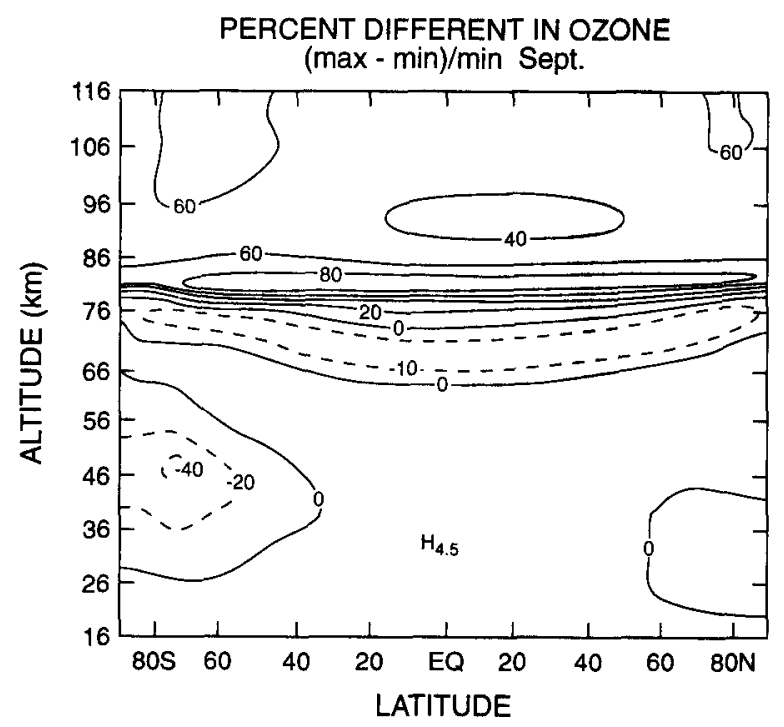

FIGURE 8. Ozone percentage change between solar minimum and maximum for September (end of Northern Hemisphere summer/Southern Hemisphere winter, from Garcia et al. (1984).

As mentioned in the introduction, a feedback mechanism that can be potentially important is the dynamical wave-mean flow interaction. This effect can most easily be examined by analyzing the zonal wind change. Zonal wind perturbation should change the wave propagation and dissipation structure, and consequently feedback into the thermal and chemical structure. Garcia et al. (1984) showed that the greatest changes in the zonal wind occur near the core of the polar night jet, with an increase of $3 \mathrm{~m} / \mathrm{s}$ at solar maximum. This is approximately the same magnitude as the zonal wind change obtained by Callis et al. (1985), in which they calculated a zonal wind change of 4 to $6 \mathrm{~m} / \mathrm{s}$ with a two-dimensional radiative equilibrium model, using specified profiles of ozone variation. The simulated zonal wind change varies between models, depending on the model itself and the specified variation in the solar flux. Huang \& Brasseur (1993) obtained a zonal wind change of less than $0.5 \mathrm{~m} / \mathrm{s}$ throughout the stratosphere. They attributed the weak response to the smaller solar flux variation used and the negative zonal wind feedback on gravity wave forcing that is included in their study. Regardless of the specified solar flux variation and the different models used, the less than $5 \mathrm{~m} / \mathrm{s}$ zonal wind change simulated by most models is at odds with the larger than $20 \mathrm{~m} / \mathrm{s}$ zonal wind change from solar minimum to solar maximum analyzed by Kodera \& Yamazaki (1990), using combined rocket and National Meteorological Center derived winds spanning slightly more than one solar cycle. One solar cycle worth of wind data are hardly enough to conclusively establish a statistical correlation with solar variation, but if the zonal wind change observed is truly solar in origin, it would imply that feedbacks involving wave-mean flow interaction currently not described in models play a crucial role in this question.

Brasseur (1993) and Huang \& Brasseur (1993) have used use a coupled radiative, chemistry, and dynamical two-dimensional model for the response simulation and the solar flux variability shown in Figure 2a. The total ozone column percentage change from solar minimum to maximum condition (Brasseur 1993) is shown in Figure 9. The change in ozone abundance is generally of the order of $1.1-1.3 \%$ at the equator, and increases with latitude. The increase with latitude is more pronounced during winter and early 


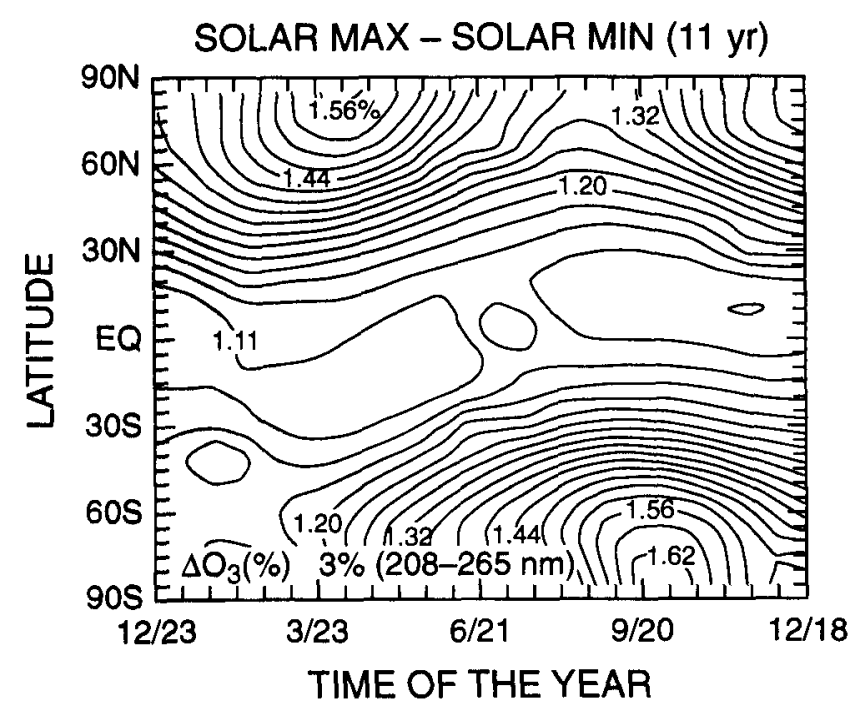

FIgURE 9. Ozone column response (expressed in percentage) as a function of latitude and time of year, from Brasseur (1993).

spring because strong planetary wave activity during this time of the year transports ozone-enhanced air masses from lower latitudes to higher latitudes. The latitude vs. height ozone concentration response is shown in Figure 10 (Huang \& Brasseur 1993) for Northern Hemisphere fall equinox. A rather small increase (1-2\%) in the stratospheric concentration of ozone is seen (except at higher latitudes) as a result of enhanced $\mathrm{O}_{2}$ photolysis in the Herzberg continuum and Schumann-Runge bands. It is worth mentioning that a recent study by Deland \& Cebula (1993) implies that the $6.6 \%$ change in the solar flux at $205 \mathrm{~nm}$ associated with the long-term solar cycle used in the model study of Huang and Brasseur may be on the low side. Thus the ozone change shown in Figure 10 probably represents the lower limit of the long-term solar cycle effect. The temperature difference between solar maximum and minimum conditions is shown in Figure 11 (Huang \& Brasseur 1993). The temperature response is limited throughout the stratosphere, with a maximum temperature increase of around $1.4^{\circ} \mathrm{K}$ near the stratopause. This is caused by an increase in ozone and a larger solar flux available for absorption by ozone during solar maximum conditions.

Although caution has to be taken when comparing models with observations since the amount of data is insufficient, the agreement between the model results and available data is unsatisfactory. Using the result from Brasseur (1993) as an example, the observed ozone response near the stratopause in the tropics (Figure 12a) is a factor 2-3 higher than the calculated response, while the opposite is found near $30-35 \mathrm{~km}$ altitude (Keating et al. 1993; Hood et al. 1993). Similarly, the temperature response (Figure $12 \mathrm{~b})$ between the model and observation is very different. The calculated temperature response in the upper stratosphere $\left(1-2^{\circ} \mathrm{K}\right)$ is much smaller than that derived from observations $\left(5^{\circ} \mathrm{K}\right)$; in addition, the signs of temperature change below $35 \mathrm{~km}$ are different. Moreover, the variation with height of the model responses does not match the profiles retrieved from observations. It is not clear why these discrepancies exist; it could involve chemical, radiative, as well as dynamical processes which are not yet fully understood. 


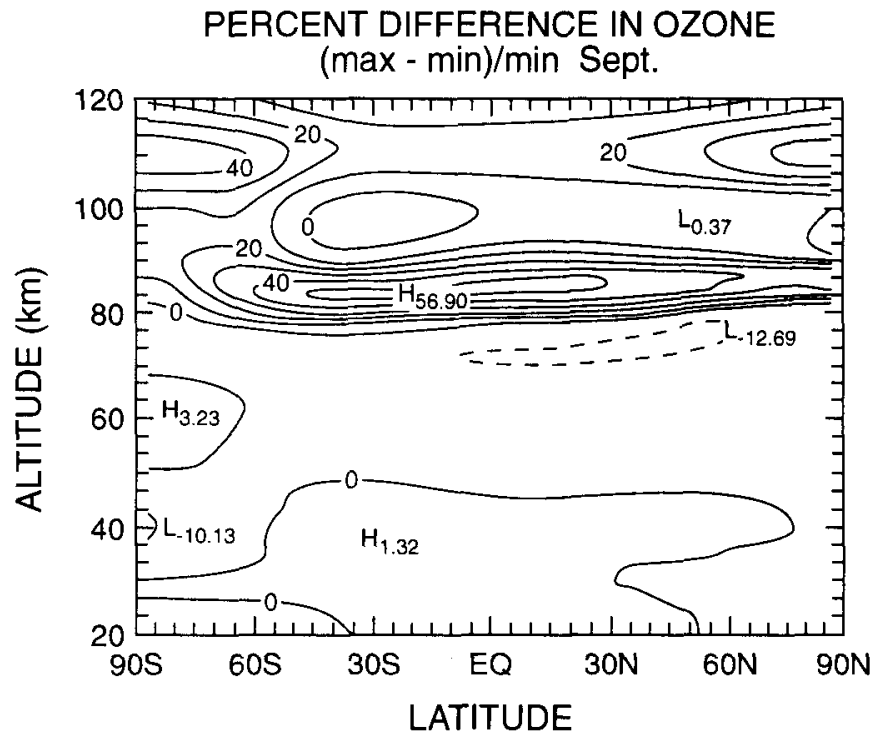

FIGURE 10. Ozone response (expressed in percentage) as a function of latitude and height for September, from Huang \& Brasseur (1993).

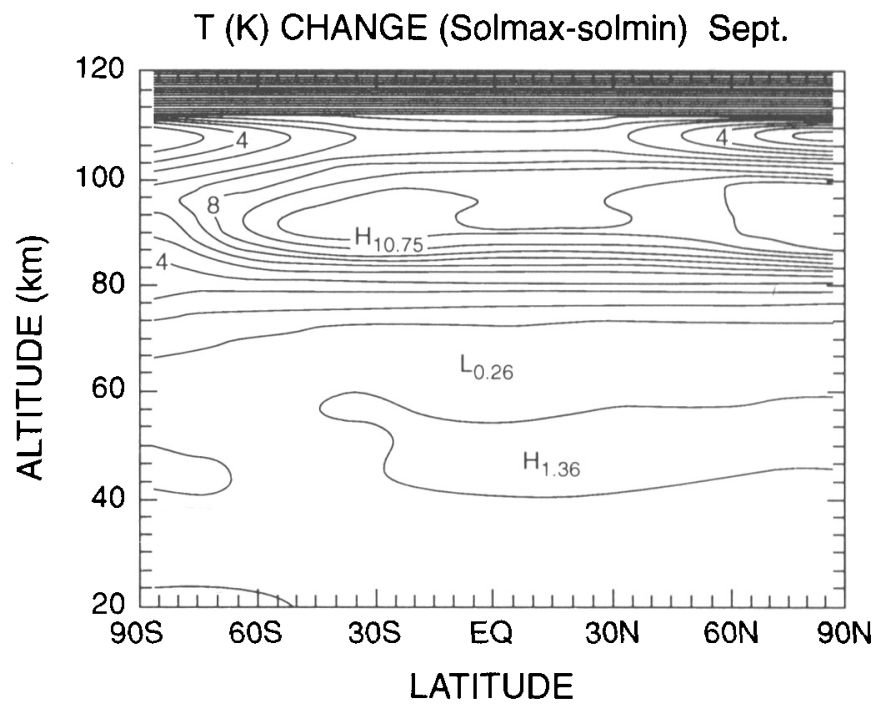

Figure 11. Temperature change $\left({ }^{\circ} \mathrm{K}\right)$ between solar minimum and maximum conditions for September, from Huang \& Brasseur (1993).

It is plausible that a three-dimensional model is needed to fully realize the true extent of the atmospheric response to solar flux change, especially in terms of the dynamical wavemean flow interaction effect. A potentially important missing link could be the effect of tropical dynamics that causes the quasi-biennial and semi-annual oscillation phenomena, since several studies suggest that quasi-biennial oscillation could be involved in the 


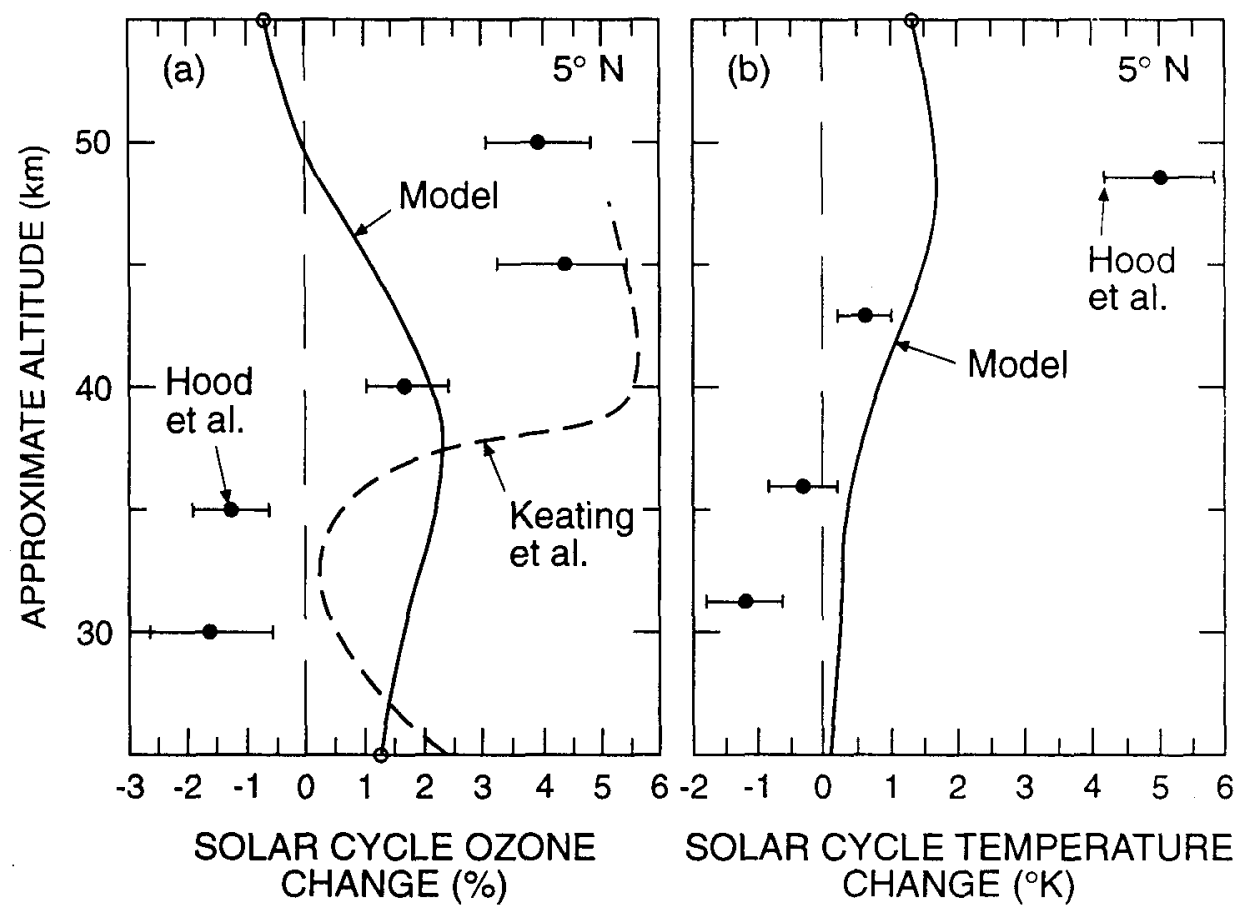

FIgure 12. Comparison between model and observed variations in (a) ozone concentration and (b) temperature at $5^{\circ} \mathrm{N}$ between 25 and $55 \mathrm{~km}$ altitude, in response to the 11-year solar cycle. The ozone variation calculated by Keating et al. (1993) is based on SBUV and SAGE II data. Hood et al. (1993) based their analysis on SBUV observations for ozone and NMC analyses for temperature, from Brasseur (1993).

response of the stratosphere to the solar cycle solar cycle (Labitzke \& van Loon 1988; Kodera 1991; Kodera et al. 1991).

\section{REFERENCES}

ANGELL, J. K. 1988 Variations and trends in tropospheric and stratospheric global temperatures, 1958-1987. J. Climate 1, 1296-1313.

ANGELL, J. K. 1991 Stratospheric temperature change as a function of height and sunspot number during 1972-89 based on rocketsonde and radiosonde data. J. Climate 4, 11701180.

Baldwin, M. P. \& Dunkerton, T. J. 1989 Observations and statistical simulations of a proposed solar cycle/QBO/weather relationship. Geophys. Res. Lett. 16, 863-867.

Brasseur, G. 1993 The response of the middle atmosphere to long-term and short-term solar variability: A two-dimensional model. J. Geophys. Res. 98, 23,079-23,091.

Brasseur, G. \& Simon, P. C. 1981 Stratospheric chemical and thermal response to long-term variability in solar UV irradiance. J. Geophys. Res. 86 7343-7362.

Brasseur, G., Rudder, A.D., Keating, G.M. \& Pitts, M.C. 1987 Response of middle atmosphere to short-term solar ultraviolet variations: 2. Theory. J. Geophys. Res. 92, 903-914.

Callis, L. B. \& Nealy, J.E. 1978 Solar UV variability and its effect on stratospheric thermal structure and trace constituents. Geophys. Res. Lett. 5, 249-252. 
Callis, L. B., Alpert, J.C. \& Geller, M.A. 1985 An assessment of thermal, wind, and planetary wave changes in the middle and lower atmosphere due to 11-year UV flux variations. J. Geophys. Res. 90, 2273-2282.

Chandra, S. 1991 The solar UV related changes in total ozone from a solar rotation to a solar cycle. Geophys. Res. Lett. 18, 837-84.

Chanin, M.L., Simres, N. \& Hauchecorne, A. 1987 Long-term variations of the temperature of the middle atmosphere at mid-latitude: dynamical and radiative causes. J. Geophys. Res. 92, 10933-10941.

Deland, M. T. \& Cebula, R.P. 1993 The composite Mg II solar activity index for solar cycles 21 and 22. J. Geophys. Res. 98, 12809-12823.

ECKMAN, R. S. 1986 The response of ozone to short-term variations in the solar ultraviolet irradiance, 1., A theoretical model. J. Geophys. Res. 91, 6695-6704.

Garcia, R. R., Solomon, S., Roble, R.G/ \& Rusch, D.W. 1984 A numerical response of the middle atmosphere to the 11-year solar cycle. Planet. Space. Sci. 32, 411-423.

Gille, J. C., Smythe, C.M. \& Heath, D.F. 1984 Observed ozone response to variations in solar ultraviolet radiation. Science $\mathbf{2 2 5}, 315-317$.

Hauchercorne, A. \& Chanin, M.L. 1980 Density and temperature profiles obtained by lidar between 35 and $70 \mathrm{~km}$. Geophys. Res. Lett. 7, 565-568.

HooD. L. L. 1986 Coupled stratospheric ozone and temperature responses to short-term changes in solar ultraviolet flux: An analysis of Nimbus 7 SBUV and SAMS data. J. Geophys. Res. 91, 5264-5276.

Hood, L. L., Huang, Z. \& Bougher, S.W. 1991 Mesospheric effects of solar ultraviolet variations: Further analysis of SME IR ozone and Nimbus 7 SAMS temperature data. $J$. Geophys. Res. 96, 12989-13002.

HOOD, L. L. \& JIRIKOWIC, J.L. 1991 Stratospheric dynamical effects of solar ultraviolet variations: Evidence from zonal mean ozone and temperature data. J. Geophys. Res. 96, 7565-7577.

Hood, L. L. \& MCCORMACK, J.P. 1992 Components of interannual ozone change based on Nimbus 7 TOMS data. Geophys. Res. Lett. 19, 2309-2312.

HooD, L. L., JiRIKowIC, J.L. \& MCCORMACK, J.P. 1993 Quasi-decadal variability of the stratosphere: Influence of long-term solar ultraviolet variations. J. Atmos. Sci. 50, 39413958 .

Huang, T.Y.W. \& Brasseur, G.P. 1993 Effect of long-term solar variability in a twodimensional interactive model of the middle atmosphere. J. Geophys. Res. 98, 20413-20427.

Keating, G. M., Pitts, M.C., Brasseur G. \& Rudder, A.D. 1987 Response of middle atmosphere to short-term ultraviolet variations: 1. Observations. J. Geophys. Res. 92, 889-902.

Keating, G. M., Chiou, L.S. \& Hsu, N.C. 1993 Coupling between middle atmosphere trend estimates and solar effects in ozone vertical structure. Adv. Space Res., in press.

KoderA, K. 1991 The solar and equatorial QBO influences on the stratospheric circulation during the early Northern-Hemisphere winter. Geophys. Res. Lett. 18, 1023-1026.

KODERA, K. 1993 Quasi-decadal modulation of the influence of the equatorial quasi-biennial oscillation on the north polar stratospheric temperatures. J. Geophys. Res. 98, 7245-7250.

KODERA, K. \& YAMAZAKI, K. 1990 Long-term variation of upper stratospheric circulation in the Northern Hemisphere in December. J. Met. Soc. Japan 68, 101- 105.

Kodera, K., ChiBa, M. \& ShiBata, K. 1991 A general circulation model study of the solar and QBO modulation of the stratospheric circulation during the Northern Hemisphere winter. Geophys. Res. Lett. 18, 1209-1212.

Labitzke, K., Naujokat, B. \& ANGell, J.K. 1986 Long-term temperature trends in the middle stratosphere of the Northern Hemisphere. Adv. Space. Res. 6, 7-16.

LABITZKe, K. \& VAN LoON, H. 1988 Associations between the 11-year solar cycle, the QBO and the atmosphere. Part I: The troposphere and stratosphere in the Northern hemisphere in winter. J. Atmos. Terr. Phys. 50, 197-206. 
LABITZKe, K. \& VAN LOON, H. 1989 Association between the 11-year solar cycle, the QBO, and the atmosphere. Part III: Aspects of the association. J. Climate 2, 554- 565.

Natarajan, M., Callis, L.B. \& Nealy, J.E. 1981 Solar UV variability: Effects on stratospheric ozone, trace constituents and thermal structure. Pure Appl. Geophys. 119, 750-779.

Penner, J. E. \& Chang, J.S. 1978 Possible variations in atmospheric ozone related to the 11-year solar cycle. Geophys. Res. Lett. 5, 817-820.

Rottman, G. J. 1988 Observations of solar UV and EUV variability. Adv. Space. Res. 8(7), $53-66$.

SAlby, M. L. \& ShEA, D.J. 1991 Correlations between solar activity and the atmosphere: An unphysical explanation. J. Geophys. Res. 96, 22579-22595.

Stolarski, R. S., Bloomfield, P., McPeters, R.D. \& Herman, J.R. 1991 Total ozone trends deduced from Nimbus 7 TOMS data. Geophys. Res. Lett. 18, 1015-1018.

Summers, M. E., Strobel, D.F. Bevilacqua, R.M., Zhu, X., Deland, M.T., Allen, M. \& KEATING, G.M. 1990 A model study of the response of mesospheric ozone to short-term solar ultraviolet flux variations. J. Geophys. Res. 95, 22523-22538.

VAN LOON, H. \& LABITZKe, K. 1988 Association between the 11-year cycle, the QBO, and the atmosphere. Part II: Surface and $700 \mathrm{mb}$ in the Northern Hemisphere in winter. J. Climate 1, 905-920.

Wuebbles, D. J., Kinnison, D.E., Grant, K.E. \& Lean, J. 1991 The effect of solar flux variations and trace gas emissions on recent trends in stratospheric ozone and temperature. J. Geomag. Geoelectr. 43, 709-718. 